\title{
ET-06-013
}

\section{A IMPORTÂNCIA DO BRINCAR NO PROCESSSO EDUCACIONAL: O QUE DIZEM AS PROFESSORAS DE UMA ESCOLA DO MUNICÍPIO DE SOBRADO-PB}

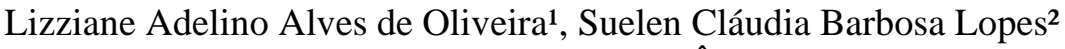 \\ ${ }^{1}$ Centro Universitário de João Pessoa - UNIPÊ. \\ ${ }^{2}$ Universidade Federal da Paraíba - UFPB.
}

\section{RESUMO}

A pesquisa teve como objetivo de estudo o lúdico no âmbito escolar. O tema, de abordagem investigativa, tem como eixo a importância do brincar no processo educacional de ensino-aprendizagem, nas séries iniciais do Ensino Fundamental. O lúdico vem sendo objeto de estudo constante principalmente no cotidiano escolar, pois o ato de brincar é inerente à criança, por conseguinte, configura-se como uma de suas necessidades básicas, uma vez que favorece o desenvolvimento motor, social, emocional e cognitivo. Logo, podemos dizer que é brincando que a criança satisfaz seus interesses e necessidades particulares, reflete e descobre o mundo que a cerca de modo particular, possibilitando a ressignificação e a reelaboração da realidade, ou seja, é no ato de brincar que toda criança se apropria da realidade imediata, atribuindo-lhe significado de acordo com suas necessidades. Diante disso, o presente artigo trata da importância da brincadeira nas séries iniciais do ensino fundamental, considerando que o lúdico vem sendo tirado do mundo infantil, ou seja, as crianças brincam cada vez menos, não havendo uma proposta pedagógica que incorpore essa prática como eixo do trabalho escolar. Buscamos, ainda, refletirmos sobre o mecanicismo observado nas práticas pedagógicas nesse nível de ensino, trazendo para discussão a presença/ausência de atividades lúdicas no cotidiano da escola. Para isso, realizamos uma pesquisa qualitativa, tendo como universo uma escola do Município de Sobrado/PB, cujo objetivo constituiu-se em analisar o espaço da brincadeira nesse ambiente. Tivemos como sujeitos dessa investigação dois professores que atuam nas séries iniciais do ensino fundamental. Como instrumento de coleta de dados, utilizamos um questionário, através do qual foi possível perceber a concepção dos sujeitos em relação à prática do brincar no cotidiano escolar.

Palavras-chave: Brincar; Ensino fundamental; Prática pedagógica.

\section{INTRODUÇÃO}

O brincar deve ser imposto no contexto cultural e educacional da criança para que possa manifestar um desenvolvimento psicomotor que contribuirá para uma formação física e intelectual. A escola, como lugar de criação, desenvolvimento, socialização que contribui para formação da cultura do aluno, tem como objetivo contribuir na formação de um cidadão crítico, integrante na sociedade, capaz de modificar o meio em que vive.

O brincar, na verdade, não é uma simples atividade, perda de tempo, como alguns pensam, mas, ao contrário, é uma ferramenta fundamental para o desenvolvimento e aprendizagem da criança.

Para as crianças, as brincadeiras permitem uma incorporação de valores, desenvolvimento cultural, assimilação de novos conhecimentos e aprimoramento de várias habilidades. A brincadeira permite a criança conhecer a si mesma, ao mesmo tempo em que apreende a sua realidade e torna-se capaz de desenvolver os seus potenciais dinâmicos, lúdicos e criativos. 
Nesse caso, faz-se necessário a conscientização dos professores em relação ao importante papel que o brincar representa no processo de aprendizagem da criança, executando um resgate do brincar, uma vez que a brincadeira vem perdendo espaço na nossa sociedade.

Está pesquisa foi realizada em uma escola do Município de Sobrado/PB, de Sobrado, denominada "Escola Estadual de Ensino Fundamental e Médio Humberto, com alunos na faixa etária de 12 aos 14 anos. A mesma teve como sujeitos dois professores do Ensino Fundamental, do período matutino, os professores um são Licenciados em Biologia e o outro de Matemática. Como instrumento de coleta de dados foi utilizado a observação entre o intervalo do recreio e algumas aulas, entre elas, a disciplina de matemática, bem como um questionário, ambas com o intuito de verificar as concepções dos professores quanto às atividades lúdicas desenvolvidas no cotidiano escolar.

\section{ASPECTOS CONCEITUAIS}

O brincar é de forma especial a maneira de viver e ser feliz. Na criança, constitui-se numa maneira dinâmica de incentivar o desenvolvimento e a aprendizagem, seja ela no âmbito escolar ou não. Logo, brincar é uma necessidade que a criança experimenta para melhor desenvolver seus potenciais harmoniosamente, adquirindo características próprias e fundamentais para seu aprendizado.

Considerando um conceito mais restrito, o dicionário traz o brincar como uma ação que implica em divertir-se, entreter-se espontaneamente, desenvolvendo atividades conjuntas. Sendo assim, constitui-se um dos pilares da constituição da cultura da infância, uma vez que, segundo Benjamim (1994), é através do brincar que a criança vê e constrói o mundo.

A brincadeira vista sob a ótica da "cultura", é transmitida de geração a geração, um instrumento de conservação dos valores sociais a serem aprendidos ainda na infância. É o que nos afirma Kishimoto (1993, p. 15), ao escrever que, “(...) enquanto manifestação da cultura popular, os jogos tradicionais têm a função de perpetuar a cultura infantil e desenvolver formas da convivência social”. Diz ainda que “(...) as imagens culturais, que ficam marcadas, são informações, valores, formados na vida cotidiana e que se refletem na forma de brincar da criança”.

Vários autores, a exemplo de Brougère (1997), Kishimoto (1993), Piaget (1978), Santos (1998), Wajskop (2007), dentre outros, têm caracterizado a brincadeira como a atividade ou ação própria da criança, sendo esta voluntária, espontânea, delimitada no tempo e no espaço, prazerosa, constituída por reforçadores positivos intrínsecos com um fim em si mesmos e tendo uma relação íntima com a criança Setúbal apud MALUF (2003, p. 18), afirma que podemos identificar o brincar em dois momentos:

1) Nas brincadeiras tradicionais, momento em que o individuo se insere na maneira coletiva;

2) Na história de vida própria do indivíduo, recorre as suas experiências no momento de brincar.

É nesse aspecto, relacionando conteúdos do passado e do presente, que a criança dá sentido ao seu existir. Diante disso, Maluf (2003, p. 20) afirma que através da brincadeira a criança se desenvolve permeada de relações cotidianas, que vão auxiliar na construção de sua identidade, na imagem de si e do mundo que o cerca. Refletindo sobre essa citação de Maluf, entendemos que o brincar constitui-se uma atividade crucial no desenvolvimento da criança. Assim sendo, privá-la de tal ação, é negá-la um direito fundamental: o direito de brincar.

Ainda sobre a importância do brincar, Brougere (2006, p.98), a criança, através do brincar vai construindo a consciência da realidade, ao mesmo tempo em que já vive uma possibilidade de modificá-la.

Stevens (apud MALUF, 2003, p. 24) diz que o brincar "é necessário e vital o desenvolvimento normal do organismo em si e para o seu amadurecimento como um ser social". 
Segundo o Referencial Curricular Nacional da Educação Infantil - RCNEI (BRASIL, 1998, p. 22) "O brincar é uma das atividades fundamentais para o desenvolvimento da identidade e da autonomia". No brincar, as crianças exploram, perguntam e refletem sobre a realidade na qual a rodeia, com o desenvolvimento psicológico e social.

Nesse sentido, é preciso pensar numa prática pedagógica que não esteja centrada apenas nos aspectos cognitivos. Para isso, a escola deve tomar como eixo do seu currículo as necessidades da criança, envolvendo, aí, o brincar. No entanto, os professores devem abrir espaço no âmbito escolar para garantir uma boa educação através de atividades lúdicas: brincando, evoluindo e modificando suas propostas pedagógicas, não considerando apenas o brincar isolado da criança, mas fazendo com que haja a participação em grupo, facilitando o relacionamento entre as crianças.

\section{REPENSANDO A PRÁTICA NAS SÉRIES INICIAIS DO ENSINO FUNDAMENTAL}

Mesmo com tantas discussões acerca da importância do brincar na escola, o que se observa, ainda, são práticas pedagógicas cansativas que em nada atraem as crianças. Não há, pois, um espaço para atividades lúdicas como forma de aprendizado e interação, estimulando e aproximando a realidade do brincar, impulsionando para o desenvolvimento cultural e intelectual das crianças.

Reiterando o que foi dito anteriormente, é difícil encontrar uma escola que realmente incentive e valorize o aprendizado através do brincar, pois algumas permanecem desenvolvendo uma metodologia tradicional, em que o brincar é considerado um tempo desperdiçado e que não vai levar a criança a lugar algum.

Nesse sentido, Bettelheim (apud MALUF, 2003, p. 18), afirma que "brincar é muito importante, pois enquanto estimula o desenvolvimento intelectual da criança, também ensina, sem que ela perceba, os hábitos necessários a esse crescimento”. Com isso, o autor defende que esses são momentos descontraídos que conseguem desinibir o intelecto da criança e estimular sua autoaprendizagem.

Vale ressaltar que as atividades lúdicas ganharam um respaldo legal e foram mencionadas no Estatuto da Criança e do Adolescente Brasileiro - ECA - (BRASIL,1990). O Artigo 16 do capítulo II do referido documento propõe o direito à liberdade para brincar, praticar esportes e se divertir.

Conforme os Parâmetros Curriculares Nacionais (1997), o uso dos jogos / brinquedos educativos com fins pedagógicos remete-nos para a relevância desse instrumento para situações de ensino-aprendizagem e de desenvolvimento infantil. O referido documento, também defende que por meio das brincadeiras, os professores podem assistir e constituir uma visão dos processos de desenvolvimento das crianças em conjunto e de cada uma em particular, registrando suas capacidades de uso das linguagens assim como suas capacidades sociais e dos recursos afetivos e emocionais que dispõem.

Diante disso, a criança não seria mais considerada um adulto em miniatura: ela vive um mundo próprio que é preciso compreender (GADOTTI, 1994). Nesse caso, a brincadeira assume um papel fundamental na infância. Numa concepção sociocultural, a brincadeira mostra como a criança interpreta e assimila o mundo de diversas maneiras inusitadas.

Devemos considerar, acima de tudo, que estamos educando as nossas crianças para vida, para um mundo cheio de diferenças culturais, étnicas e precisamos encontrar maneiras para fazer valer estas diferenças diante uma sociedade cheia de preconceitos que ainda não está preparada para saber lidar com importunas situações, estimulando e compreendendo o desejo da criança.

É importante salientar que o brincar em situações educacionais, proporciona, não só um meio real de aprendizagem como permite também que adultos perceptivos e competentes aprendam sobre as crianças e suas necessidades. Na escola, isso significa professores capazes de compreender melhor a aprendizagem e desenvolvimento geral, aos quais surgem oportunidades de se reavaliarem sobre novas aprendizagens. 
No entanto, alguns professores estão preocupados com os repasses dos conteúdos pedagógicos e esquecem que o brincar necessita de um espaço em sua prática, pois é evidente que a brincadeira é essencial para o desenvolvimento da criança. Muitos educadores até entendem teoricamente a importância das brincadeiras, porém não realizam essas atividades na prática, devido a cobrança tanto por parte da escola como dos pais. Em alguns casos são os próprios professores que não desenvolvem este ato, dando ênfase à área cognitiva da criança.

O educador deve inserir a atividade lúdica na sua prática pedagógica, resistindo a qualquer pressão, como a listagem de conteúdos a serem vencidos e a cobrança dos pais. Nesse caso, a sala de aula se transformará num espaço de maior criatividade, liberdade e ludicidade, no qual a criança possa desenvolver sua autonomia. Essa seria uma forma de organizar e abrir espaço para observar a criança de forma espontânea e dinâmica, em busca de uma formação de individuo reflexivos, criativos e capazes de enfrentar desafios, proporcionando condições para que a criança brinque de forma voluntariamente, oportunizando a ela momentos de prazer e alegria no ambiente escolar, tornando-se autora de suas criações e não mera copiadora.

No entanto, para que o professor aceite o brincar infantil, é fundamental que ele permita-se brincar e sentir-se como uma criança, pois o encontro com o brincar lhe exige uma disponibilidade para acolher a brincadeira das crianças em toda a sua plenitude, com toda a curiosidade própria da infância que é colocada em jogo. Esse é o desafio para o professor, pois se faz necessário que ele aberto e disposto a brincar e criar meios que possibilite a mudança no âmbito escolar.

De acordo com Freire (2002, p.45), "se a brincadeira é tão prazerosa e transmite conhecimentos importantes para o processo de formação desse cidadão, visto que vem carregado de um contexto histórico, não há porque deixá-la do lado de "fora" da escola ".

As brincadeiras não podem ser vista como "uma brincadeira" de criança. É incompreensível desconsiderar a quantidade de informações que são captadas através das brincadeiras, e a escola/professor tem relegado essa rica atividade a um segundo plano.

Diante disso, se faz necessário um novo pensar das práticas pedagógicas, para que efetivamente possa haver uma transformação, uma mudança no caminho das habilidades apresentadas pelas crianças em tosos os seus aspectos (psicomotores, cognitivos, emocionais, culturais).

Não é suficiente o professor se preocupar apenas com os conteúdos e métodos em sua prática pedagógica, mas, sobretudo refletir sobre o processo de ensino-aprendizagem. Trata-se, portanto, de desenvolver e ampliar o mundo lúdico da criança, respeitando seus interesses e necessidades.

A ludicidade é uma necessidade do ser humano em qualquer idade e não pode ser vista apenas como diversão. O desenvolvimento do aspecto lúdico facilita a aprendizagem, o desenvolvimento pessoal, social e cultural, colabora para uma boa saúde mental, prepara para um estado interior fértil, facilita os processos de socialização, comunicação, expressão e construção do conhecimento.

É bom lembrar que através do brincar livre e exploratório, as crianças aprendem um pouco sobre situações, pessoas, atitudes, respostas, texturas, atributos visuais, auditivos e cenestésicos. É no brincar que a criança usa a sua imaginação, e é no criar que se brinca com as imagens simbólicas, fazendo uso do próprio potencial, livre e inteligente.

É brincando que a criança constrói um conhecimento sobre si mesmo e sobre o mundo. Nas brincadeiras, ela desenvolve algumas capacidades importantes, tais como atenção, a imitação, a memória, a imaginação, além da socialização e da capacidade de escolha sendo um ser ativo de seu desenvolvimento.

Vale ressaltar que quanto mais jovem a criança, mais provável que seja necessário o brincar em suas experiências, tanto na escola como no ambiente familiar. 
De acordo com o Referencial Curricular Nacional para Educação Infantil - RCNEI (1998, p. 29),

\begin{abstract}
Cabe ao professor organizar situações para que as brincadeiras ocorram de maneira diversificada para propiciar às crianças a possibilidade de escolherem os temas, papéis, objetos e companheiros com quem brincar [...] e assim elaborarem de forma pessoal e independente suas emoções, sentimentos, conhecimentos e regras sociais.
\end{abstract}

Assim, o professor deve reconhecer o ato de brincar como recurso pedagógico em sala de aula. Quanto mais significativas são as atividades oferecidas, mas existem interesses da criança em participar e se inserir no ambiente escolar.

\title{
METODOLOGIA
}

Está pesquisa foi realizada em uma escola do Município de Sobrado/PB, de Sobrado, denominada "Escola Estadual de Ensino Fundamental e Médio Humberto, com alunos na faixa etária de 12 aos 14 anos. A mesma teve como sujeitos dois professores do Ensino Fundamental, do período matutino, os professores um são Licenciados em Biologia e o outro de Matemática. Como instrumento de coleta de dados foi utilizado a observação entre o intervalo do recreio e algumas aulas, entre elas, a disciplina de matemática, bem como um questionário, ambas com o intuito de verificar as concepções dos professores quanto às atividades lúdicas desenvolvidas no cotidiano escolar.

A pesquisa teve como objetivo de estudo o lúdico no âmbito escolar. O tema, de abordagem investigativa, tem como eixo a importância do brincar no processo educacional de ensino-aprendizagem, nas séries iniciais do Ensino Fundamental. Diante disso, foi observado o desenvolvimento das crianças e professores baseado no contexto pedagógico e nas condições histórico-sócio-cultural do ambiente em que estão situados.

A pesquisa foi desenvolvida através da observação do comportamento dos alunos nas aulas de ciências e de matemática, durante o período de duas semanas. Em seguida foi trabalhado em sala de aula o lúdico, desenvolvendo junto com os professores brincadeiras e atividades lúdicas que envolvesse os alunos e conseguisse ampliar a forma de transmissão e aprendizado. Com a utilização de recursos pedagógicos e áudio visual como jogos, leituras, imagens, música.

\section{OBJETIVOS}

- Observar a metodologia pedagógica do ensino-aprendizagem no ensino fundamental na disciplina de ciências;

- Verificar as concepções dos professores quanto às atividades lúdicas desenvolvidas no cotidiano escolar;

- Utilizar o lúdico no processo de ensino aprendizagem;

- Comparar a metodologia aplicada no âmbito escolar;

\section{RESULTADOS E DISCUSSÃO}

Esta pesquisa teve como referencial de análise uma Escola do Município de Sobrado, denominada "Escola Estadual de Ensino Fundamental e Médio Humberto Lucena". Dois professores da referida escola, uma graduada em Pedagogia e o outro com formação incompleta em Licenciatura em Matemática, constituíram-se os sujeitos desta pesquisa. Assim como a denominação da escola, para preservar o seu anonimato, substituímos seus nomes por P1 e P2. 
Como instrumento de coleta de dados nos utilizamos da observação, realizada no período de três dias, e da aplicação de um questionário, ambos com o intuito de verificar as concepções dos professores quanto às atividades lúdicas desenvolvidas no cotidiano escolar.

As opiniões circularam em torno da importância da brincadeira na escola, a periodicidade em que o lúdico acontece no cotidiano escolar e a valorização do lúdico na aprendizagem significativa.

Assim, quando arguidos sobre de que forma o lúdico está inserido no planejamento e qual importância possui na prática pedagógica, os pesquisados apresentam respostas contrárias, conforme veremos abaixo:

Elaboro meu plano de aula de acordo com o planejamento que tenho, não abro muito espaço para as crianças brincarem, pois se torna bagunça e fica difícil de controlá-la, nas minhas aulas não utilizo muitas brincadeiras porque não acredito que vai estimular as crianças a aprenderem mais (P1).

Para mim o lúdico é de extrema importância, para poder conseguir realizar minhas práticas pedagógicas com satisfação e obter um bom resultado dos alunos em sala de aula, abrangendo meus objetivos de modo que corresponda ao esperado, ou seja, que os alunos aprendam de forma espontânea (P2).

Conforme observamos, a professora 1 desenvolve uma prática pedagógica baseada no método tradicional, não deixando espaço para que as crianças tenham este momento de descontração, tornando a aula monótona. A mesma é bastante enfática quando diz que não acredita que as brincadeiras possam auxiliar no processo ensino-aprendizagem das crianças. Essa postura nos deixa surpresa, haja vista que a referida professora é graduada em Pedagogia. Este é um dilema a ser questionado.

Já o professor 2 demonstra uma postura mais flexível, pois utiliza o lúdico na sua prática pedagógica diariamente. Percebe-se que realmente ele quer fazer a diferença, tornando a aula descontraída e estimuladora, fazendo com que os alunos se interessem e aprendam mais rápido.

Apesar desse professor não possuir ainda a graduação, usa estratégias dinâmicas e interessantes para tornar sua aula agradável. Dessa forma, os alunos se sentem à vontade com o professor em sala de aula. esclarece:

A respeito da importância das brincadeiras, Winnicott (apud MALUF, 2003, p. 82),

\begin{abstract}
A brincadeira é a própria saúde, ela traz a oportunidade para o exercício da essência e do equilíbrio humano. Através dos gestos realizados pela criança durante as brincadeiras, expressam suas intenções, contradições, todas as tensões tornam-se visíveis e perceptíveis.
\end{abstract}

Além disso, entendemos que é brincando que a criança reflete e descobre o mundo que a cerca de modo particular, possibilitando a ressignificação e a reelaboração da realidade, ou seja, é no ato de brincar que toda criança se apropria da realidade imediata, atribuindo-lhe significado de acordo com suas necessidades.

Para Brougére (2006, p.59), “a brincadeira, além de proporcionar prazer e diversão, pode representar desafios e provocar o pensamento reflexivo da criança".

Considerando o pensamento de Maluf (2003), quando brincamos exercitamos nossas potencialidades, provocamos o funcionamento do pensamento, adquirimos conhecimento sem estresse ou medo, desenvolvemos a sociabilidade, cultivamos a sensibilidade, nos desenvolvemos intelectualmente, socialmente e emocionalmente.

Em relação às dificuldades que o educador encontra para realizar um trabalho envolvendo jogos e brincadeiras, a professora 1 enfatiza a desorganização da sala de aula e a falta de controle dos alunos, revelando mais uma vez a banalidade com que trata o brincar. 
Quando realizo estas brincadeiras ou jogos a sala fica desorganizada os alunos começam a gritar e não consigo mais ter controle (P1).

Contrário a esse pensamento, o professor 2 deixa claro a importância de atividades lúdicas no processo de desenvolvimento da criança.

Não consigo identificar isso com dificuldades, porque para mim é satisfação e percebo que os alunos mais ainda. Consigo tornar a aula agradável, envolvendo com brinquedos e jogos, confeccionado por eles mesmo, com recursos reaproveitáveis.

Vale ressaltar que a brincadeira não pode mais ser vista como algo banal, que não deve ser realizado na escola, pois diante deste estudo percebemos que o brincar apresenta várias peculiaridades tanto no que diz respeito à cognição da criança, como em outras diversas áreas, a exemplo da coordenação motora, a desenvoltura na comunicação e na linguagem bem como na interação entre o contexto social e cultural ao qual a criança está inserida.

Dando continuidade aos nossos questionamentos, pedimos que os referidos professores enumerassem algumas atividades lúdicas que fazem parte do seu cotidiano. Nesse ponto, observamos que a professora 1, mesmo não dando importância as atividades lúdica, promove algumas brincadeiras, tais como: "Brincar com quebra-cabeça, jogos de bola e pintura".

O professor 2 revela um maior compromisso com as atividades lúdicas ao elencar uma variedade de ações: confecção de fantoche, boliche, quebra-cabeça, instrumentos musicais, modelagem com sucata, teatro, jogos de números e jogos de palavras. Percebe-se, com isso, que o professor 2 organiza suas aulas de acordo com os Parâmetros Curriculares Nacionais - PCN's, proporcionando um bem estar, um desempenho natural e excepcional das crianças ao lidarem com o lúdico e, ao mesmo tempo, transformando e organizando o seu conhecimento e explorando uma relação do brincar na sala de aula diferente da que é proporcionada em casa.

Esse fato é de grande importância, uma vez que as crianças têm oportunidade de experimentar, explorar e investigar, através do lúdico.

Segundo Moyles (2002, p.29):

O brincar deve ser aceito como um processo, não necessariamente com algum resultado, mas capaz de um resultado se o participante assim o desejar; O brincar é necessário para as crianças e para os adultos; O brincar não é o oposto do trabalho, ambos são partes da nossa vida; O brincar é sempre estruturado pelo ambiente, pelos materiais ou contextos em que ocorre; A exploração é uma preliminar de formas mais desafiadoras do brincar que, no ambiente escolar, são as que provavelmente serão dirigidos pelo professor; $\mathrm{O}$ brincar adequadamente dirigido assegura que a criança aprende a partir de seu atual estado de conhecimento e habilidade; Os pais tem o direito de esperar que o brincar na escola seja significada e diferentemente organizado do brincar em cãs e em qualquer outro lugar. Se isso pode ser comprovado, é mais provável que eles atribuam valor e importância a ele. O brincar é potencialmente um excelente meio de aprendizagem.

Enfim, os processos de desenvolvimento e de aprendizagem envolvidos no brincar são constitutivos do processo de apropriação de conhecimentos. A possibilidade de imaginar, de ultrapassar o já dado, de estabelecer novas relações, de inverter a ordem, de articular passado, presente e futuro potencializam nossas possibilidades de aprender sobre o mundo em que vivemos. 


\section{CONCLUSÃO}

Conforme discutimos ao longo deste estudo, o brincar constitui-se uma atividade fundamental no desenvolvimento da criança. Nesse caso pode-se concluir que o brincar deve assumir um lugar especial na escola, na sala de aula e no planejamento do professor, pois, com isso, a criança desempenha melhor suas atividades, uma vez que se sente livre e motivada.

Mas é necessário despertar nos professores o desejo pelo brincar, o que implica numa nova postura de pais e educadores diante da brincadeira e do espaço em que ela acontece. Espera-se que os espaços se tornem em espaços prazerosos, cheios de desafios, emoções e descobertas.

Enfatizamos, ainda, que ao brincar, uma criança dá muitas informações e comunica, por meio da ação, sua forma de pensar, e o observador precisa estar preparado para reconhecer nas atitudes das crianças, ações ou procedimentos que retratem os indícios dos critérios necessários para uma boa formação cognitiva, e até afetiva-social do aluno.

Por fim, concluímos que quanto mais o adulto vivenciar sua ludicidade, maior será a chance deste profissional trabalhar com a criança de forma prazerosa, enquanto atitude de abertura às práticas inovadoras.

Em síntese, as brincadeiras expressam possibilidades de uma pedagogia diferenciada das normalmente aplicadas, permitindo ao professor criar e gerir situações de aprendizagem mais condizentes com as atuais condições educacionais.

\section{REFERÊNCIAS}

BENJAMIN. W. Magia e técnica, arte e política. São Paulo: Brasiliense, 1994.

BENJAMIN. W. Estatuto da Criança e do Adolescente, Lei ${ }^{\circ}$ 8.069,13 de julho de 1990. Distrito Federal. Editor e distribuidor: Subsecretaria de Educação Técnicas. Senado Federal.

BENJAMIN. W. Referencial curricular nacional para a Educação Infantil. Ministério da Educação e do Desporto, Secretaria da Educação Fundamental. Brasília: MEC, 1998. 3 v.

BENJAMIN. W. Parâmetros curriculares nacionais: introdução aos parâmetros curriculares nacionais. Brasília: MEC/SEF,1997.

BROUGERE, G. Brinquedo e cultura. São Paulo: Cortez, 2006.

FREIRE, P. Pedagogia da autonomia: saberes necessários à prática educativa. 22 ed. São Paulo: Paz e Terra, 2002.

GADOTTI, M. Histórias de idéias pedagógicas. 2. ed. São Paulo: Ática, 1994.

KISHIMOTO, T. M. Jogos infantis: o jogo a criança e a educação.

MOYLES, J. R. Só brincar? O papel do brincar na Educação infantil. Porto Alegre; Artmed Editora,2002.

WAJSKOP, Gisela. Brincar na pré-escola. 7 ed. São Paulo: Cortez, 2007. 